\title{
Connexin32-mediated antitumor effects of suicide gene therapy against hepatocellular carcinoma: In vitro and in vivo anticancer activity
}

\author{
LUN WU ${ }^{1}$, WEN-BO ZHOU ${ }^{1}$, FENG SHEN ${ }^{1}$, WEI LIU ${ }^{2}$, HONG-WEI WU ${ }^{1}$, SHI-JI ZHOU ${ }^{3}$ and SHENG-WEI LI ${ }^{4}$ \\ ${ }^{1}$ Department of Hepatobiliary Surgery, Experiment Center of Medicine, Dongfeng Hospital, Hubei University of Medicine, \\ Shiyan, Hubei 442001; ${ }^{2}$ Department of Obstetrics, Haikou Hospital of Maternal and Child Health, \\ Haikou, Hainan 570100; Departments of ${ }^{3}$ Gastrointestinal Surgery and ${ }^{4}$ Hepatobiliary Surgery, \\ The Second Affiliated Hospital of Chongqing Medical University, Chongqing 400010, P.R. China
}

Received March 4, 2015; Accepted January 7, 2016

DOI: $10.3892 / \mathrm{mmr} .2016 .4895$

\begin{abstract}
Normal hepatocytes express connexin32 (Cx32), which forms gap junctions at cell-cell contact areas. The aim of the present study was to investigate whether Cx32 mediates the cell death-inducing effects of ultrasound microbubbles carrying the herpes simplex virus thymidine kinase (HSV-TK) suicide gene against hepatocellular carcinoma cells in vitro and in vivo. HepG2 cells were exposed to different concentrations of trans-retinoic acid (ATRA) in culture, to evaluate the intrinsic antitumor effect of ATRA. Detailed in-vitro and in-vivo investigations on the antitumor effects of ATRA via Cx32 mediation were performed, and the possible underlying mechanisms of action of the compound were then examined. The gene expression of HSV-TK transfected by ultrasound wave irradiation in the HepG2 cells was quantified using reverse transcription-quantitative polymerase chain reaction analysis. The effects on cell death were assessed using an MTT assay. The protein expression levels of Cx32 in ATRA-untreated or ATRA-treated tissues were quantified by immunohistochemical analysis and Western blot assays. The HSV-TK gene was successfully transfected into the HepG2 cell using ultrasound wave irradiation, and was stably expressed. Compared with the other groups, the HSV-TK gene group treated with ATRA exhibited an increased number of apoptotic cells $(\mathrm{P}<0.05)$ and improved tumor suppression $(\mathrm{P}<0.05)$. ATRA significantly increased the expression of $\mathrm{Cx} 32$ in the hepatoma tissues $(\mathrm{P}<0.01)$. The present study demonstrated that ATRA elevated the protein expression of
\end{abstract}

Correspondence to: Professor Sheng-Wei Li, Department of Hepatobiliary Surgery, The Second Affiliated Hospital of Chongqing Medical University, 76 Linjiang Road, Yuzhong, Chongqing 400010, P.R. China

E-mail: lishengwei11@163.com

Key words: connexin32, all-trans retinoic acid, herpes simplex virus thymidine kinase suicide gene, hepatocellular carcinoma
Cx32 and enhanced the bystander effect of the HSV-TK/GCV suicide gene therapy system, which may provide a potential strategy for hepatocellular carcinoma treatment.

\section{Introduction}

Hepatocellular carcinoma (HCC) is the fifth most common type of malignant tumor worldwide, and the third most common cause of cancer-associated mortality, with surgical resection remaining the most effective therapy (1). However, $<15 \%$ of patients benefit from this treatment due to the presence of multiple tumor nodules (2). Therefore, it is imperative to identify novel therapeutic strategies, including suicide gene therapy, in which nucleic acids encoding specific therapeutic genes are used as antitumor agents. Cancer gene therapy offers potential for decreasing tumor-associated mortality rates. However, it has been clinically limited by non-targeted and insufficient gene transfer (3). Ultrasound-targeted microbubble destruction-targeted gene delivery to the tumor tissue, and the targeted co-delivery of genes synergistically improves antitumor effects (3).

The present study evaluated the use of gene therapy to target HCC, using the herpes simplex virus thymidine kinase/ganciclovir (HSV-TK/GCV) suicide gene system via its 'bystander effect'. It is not a requirement that all tumor cells are directly targeted, and the occurrence of the bystander effect in HSV-TK/GCV therapy may represent an important therapeutic opportunity (4). There is compelling evidence demonstrating that gap junctional intercellular communication (GJIC) is directly involved $(5,6)$. Gap junctions are formed by connexins, a family of homologous proteins, which directly link the cytoplasms of adjacent cells to allow the passage of ions (4). Connexins can also act as tumor suppressor genes (7). GJIC is involved in tissue homeostasis, whereas the expression of connexin32 (Cx32) remains expressed and is critical for intercellular communication (8). Alternatively, a number of classes of chemicals, including gemcitabine (9) and cAMP (10), have been reported to increase $\mathrm{Cx} 26$ and $\mathrm{Cx} 43$ and, subsequently, GJIC. An ideal wide-spectrum chemical inducer of GJIC is trans-retinoic 
acid (ATRA), which results in upregulated expression levels of Cx43 and GJIC $(11,12)$.

Therefore, the present study hypothesized that treatment of tumor cells with ATRA augments the bystander effect of the HSV-TK/GCV system and results in improved tumor cell death-inducing effects by enhancing GJIC. In the present study, the effect of ATRA on the bystander-mediated cell death of HepG2 cells were examined in vitro and in vivo, and whether facilitating gap junction communication through Cx32 overexpression can increase the therapeutic efficacy of suicide gene therapy.

\section{Materials and methods}

Chemicals and reagents. Rabbit anti human Cx32 antibody was purchased from Bioworld Technology, Inc. (St. Louis Park, MN, USA). ATRA and (GCV) were purchased from Sigma-Aldrich (St. Louis, MO, USA). The total expression plasmid vector of the enhanced green fluorescent protein and HSV-TK I type (pIRES2-EGFP-HSV-TK) was constructed previously at the Institute of Ultrasound Imaging of Chongqing Medical University (Chongqing, China) (13). UTG 1025, a self-made ultrasonic gene transfection instrument and lipid microbubbles were provided by the Institute of Ultrasound Imaging of Chongqing Medical University (Chongqing, China).

Cell line and experimental animals. The HepG2 human hepatoma cell line was obtained from the Cell Resource Center, Chinese Academy of Medical Sciences, Peking Union Medical College (Beijing, China), and cultured in high glucose Dulbecco's modified Eagle's medium containing 10\% fetal bovine serum (FBS; HyClone Laboratories, Inc., Logan, UT, USA), at $37^{\circ} \mathrm{C}$ in $5 \% \mathrm{CO}_{2}$. The viability of the HepG2 cells, determined by trypan blue ( $0.4 \%$; Sigma-Aldrich) exclusion, was $>95 \%$.

A total of 32 male athymic BALB/c nu/nu mice (4-6 weeks old, weighing $20 \pm 2 \mathrm{~g}$ ) were purchased from the Laboratory Animal Center of Chongqing Medical University. They were housed at a temperature of $25^{\circ} \mathrm{C}$, under a 12-h light/dark cycle, in specific pathogen-free conditions and received food and water ad libitum. Each mice was inoculated subcutaneously with $0.2 \mathrm{ml}$ HepG 2 cells $\left(5 \times 10^{6}\right.$ cells per mouse) in suspension in the right flank. The experimental animals, with tumor diameters measuring $0.5-1.0 \mathrm{~cm}$, were randomly divided into the following four groups ( $n=8$ per group): (A) phosphate-buffered saline (PBS), (B) HSV-TK, (C) ATRA and (D) HSV-TK+ATRA. Each group contained eight mice. All protocols were approved by the Animal Experimentation Ethics Committee of Chongqing Medical University, in compliance with the recommended National Institutes of Health guidelines for the care and use of animals for scientific purposes (14).

Plasmid preparation and the combining of microbubbles with the plasmid. The pIRES2-EGFP-HSVTK gene plasmid for transfection was extracted and purified using a Tiangen kit (cat. no. RM204-01; Tiangen Biotech Co., Ltd., Beijing, China); the concentration of the isolated plasmid DNA was determined at an absorbance of $260 / 280=1.9$ by ultraviolet spectrophotometry
(U-0080D; Hitachi High-Technologies Corp., Tokyo, Japan), and resuspended to a final concentration of $1 \mu \mathrm{g} / \mu \mathrm{l}$ in $\mathrm{ddH}_{2} \mathrm{O}$ (Beyotime Institute of Biotechnology, Shanghai, China). The recombinant plasmid was evaluated using biomaging systems (GelGDoc2000; Bio-Rad Laboratories GmbH, München, Germany). The method used for the preparation of the gene-loaded lipid microbubbles was performed, according to the criteria described by Wang et al (15). The prepared blank lipid microbubbles and plasmid were then mixed $(1 \mathrm{mg} / \mathrm{ml})$ and incubated at $37^{\circ} \mathrm{C}$ for $30 \mathrm{~min}$, and the gene-loaded lipid microbubbles were produced.

Ultrasound microbubble-mediated transfection with the pIRES2-EGFP-HSVTK gene. The plasmid concentration was adjusted to $0.2 \mu \mathrm{g} / \mathrm{ml}$, mixed with the lipid microbubbles and incubated at $37^{\circ} \mathrm{C}$ for $30 \mathrm{~min}$, as described above. The microbubbles containing the pIRES2-EGFP-HSVTK plasmid were added to each well and exposed to ultrasonic (UTG 1025, Institute of Ultrasound Imaging of Chongqing Medical University) radiation ( $\left.1 \mathrm{MHz} ; 0.5 \mathrm{~W} / \mathrm{cm}^{2} ; 30 \mathrm{sec}\right)$. In order to obtain the positive clone ( $\mathrm{TK}^{+}$) HepG2 cells (density, 80-90\%), the HSV-TK-transfected cells were selected using G418 culture media (800 mg/ml; HyClone Laboratories, Inc.).

Reverse transcription-quantitative polymerase chain reaction $(R T-q P C R)$ analyses of the transfection and expression of the pIRES2-EGFP-HSV-TK gene. At 2 weeks following the observation of HepG2 cells stably expressing HSV-TK, total RNA was extracted from the HepG2 cells and quantified using RNA Isolation Solvent (Omega Bio-tek, Inc., Doraville, GA, USA) according to the manufacturer's instructions and reverse transcribed, using an RT-PCR kit (Promega Corporation, Madison, WI, USA) according to the manufacturer's protocol. The RNA $(1 \mu \mathrm{g})$ was used to synthesize cDNA (Thermo Fisher Scientific, Inc., Waltham, MA, USA). The relative transcription of HSV-TK was determined by performing semi-quantitative PCR analyses of HSV-TK, $\mathrm{TK}^{+}$cells (positive control) and $\beta$-actin (internal control) by qPCR amplification using a Rotor-Gene 6000 PCR machine (Corbett Life Science, Mortlake, Australia). The forward primer was 5'-CAGCAA GAAGCCACGGAAGT-3' and the reverse primer was 5'-AGC ACCCGCCAGTAAGTCAT-3' (Sangon Biotech Co., Ltd., Shanghai, China). For qPCR amplification, a $20 \mu 1$ reaction volume, containing $10 \mu \mathrm{l}$ 2X Taq PCR Master mix (Thermo Fisher Scientific, Inc.), $1 \mu 11 \mathrm{X}$ each primer, $2 \mu 1$ 2-fold diluted cDNA and $6 \mu$ l RNase-free water (Thermo Fisher Scientific, Inc.) was used. The amplification conditions were as follows: $94^{\circ} \mathrm{C}$ for $2 \mathrm{~min}$, followed by 28 cycles of $94^{\circ} \mathrm{C}$ for $15 \mathrm{~min}, 58^{\circ} \mathrm{C}$ for $10 \mathrm{~min}$ and $72^{\circ} \mathrm{C}$ for $30 \mathrm{~min}$, and a final step at $72^{\circ} \mathrm{C}$ for $10 \mathrm{~min}$. The expected lengths of the HSV-TK was $1,327 \mathrm{bp}$. A total of $10 \mu \mathrm{l}$ of each PCR product was loaded onto a $1.5 \%$ agarose gel $(0.5 \mu \mathrm{g} / \mathrm{ml}$ ethidium bromide; Sigma-Aldrich) and separated by electrophoresis. The expression of HSV-TK was quantified using Image-Pro Plus 5.0 software (Media Cybernetics, Inc., Rockville, MD, USA).

Assessment of the effects of ATRA and GCV on the growth of mixed cells. Prior to proceeding with comparisons of the HSV-TK/GCV-mediated bystander effect, it was important to ensure that ATRA itself had no effect on in vitro growth 
rates or cell death in the cell lines used in the present study. The HepG2 cells were plated at a density of $5 \times 10^{3}$ cells/well. The cell culture media, containing varying concentrations of ATRA $\left(0,10^{-4} \cdot 10^{-5}, 10^{-6}, 10^{-7}\right.$ and $\left.10^{-8} \mathrm{~mol} / \mathrm{l}\right)$ were replaced every day. Following 3 days incubation at $37^{\circ} \mathrm{C}, 20 \mu \mathrm{l}$ MTT assay mix was added to each well. The plates were incubated for $4 \mathrm{~h}$ at $37^{\circ} \mathrm{C}$, and the absorbance was measured at $570 \mathrm{~nm}$ (U-0080D), following which the optical density (OD570) was calculated. The same method to used to assess the cytotoxicity of GCV at varying concentrations $(0,20,40,60,80$ and $100 \mu \mathrm{g} / \mathrm{ml})$. The inhibition ratio was calculated as follows: Inhibition ratio $=\left(1-\mathrm{OD}_{\text {experiment }} / \mathrm{OD}_{\text {control }}\right) \times 100 \%$. Each assay was repeated three times.

ATRA treatment to assess the bystander effect of HSV-TK in vitro. The HSV-TK-transfected $\left(\mathrm{TK}^{+}\right)$cells were mixed with untransfected HSV-TK (TK) cells at concentrations between 0 and $100 \%$. These mixtures were plated in 96-well culture plates at a density of 4,000 cells/well in $100 \mu 1$ media with $\left(10^{-6} \mathrm{~mol} / \mathrm{l}\right)$. or without ATRA. There were four duplicate wells plated for each mixture of cells. When the cells were $20-30 \%$ confluent, with the majority of cells showing visible contact with adjacent cells, the medium was removed and replaced with complete medium containing GCV $(40 \mu \mathrm{g} / \mathrm{ml})$. The cells were incubated for 3 days at $37^{\circ} \mathrm{C}$ with or without ATRA $\left(10^{-6} \mathrm{~mol} / \mathrm{l}\right)$. The assessment of cell number was determined using an MTT $\left(20 \mu 1,37^{\circ} \mathrm{C}, 0.5 \mathrm{mg} / \mathrm{ml}\right)$ colorimetric cell proliferation assay, which measures viable cell dehydrogenase activity. The experiment was repeated three times.

\section{In vivo experiments}

ATRA administration in vivo. The mice were subcutaneously injected with HepG2 cells, as described above, and when the tumor diameter reached $0.5-1.0 \mathrm{~cm}$, the microbubbles containing the HSV-TK plasmid $(200 \mu \mathrm{l} ; 0.1 \mu \mathrm{g} / \mu \mathrm{l})$ were injected into the tumor foci of groups B and D (once every 3 days, five times). Subsequently, the ultrasonic gene transfection instrument was used to irradiate the tumor $(1 \mathrm{MHz}$; $\left.2 \mathrm{~W} / \mathrm{cm}^{2} ; 5 \mathrm{~min}\right)$, and GCV (100 mg/kg·day) was administered into the peritoneal cavity following irradiation for 14 consecutive days. In groups C and D, ATRA (1 mg/kg-day; no antitumor effect) was administered into the peritoneal cavity consecutively for 14 days. PBS $(200 \mu \mathrm{l})$ was injected into the tumor foci in group A.

Tumor sizes were measured every 3 days, and the volumes were calculated using the following equation: [(longest diameter) $\mathrm{x}$ (shortest diameter) ${ }^{2} / 2$ ]. The tumor inhibition rate was calculated as follows: Inhibition rate $=(\mathrm{PBS}$ group - mean tumor volume in treatment group) / mean tumor volume in control group x $100 \%$.

Immunohistochemical analysis. The mice were anesthetized with pentobarbital $(0.03 \mathrm{mg} / 100 \mathrm{~g}$; Sigma-Aldrich) prior to sacrifice following treatment in each group. Tumor tissues were fixed in 10\% zinc-buffered formalin (Sigma-Aldrich), embedded in paraffin (Sigma-Aldrich), sectioned (4 $\mu \mathrm{m})$, and stained with hematoxylin and eosin (Beyotime Institute of Biotechnology). To avoid nonspecific staining, avidin and biotin in the tissues were blocked using a blocking kit. Following the blocking reaction, the slides were incubated

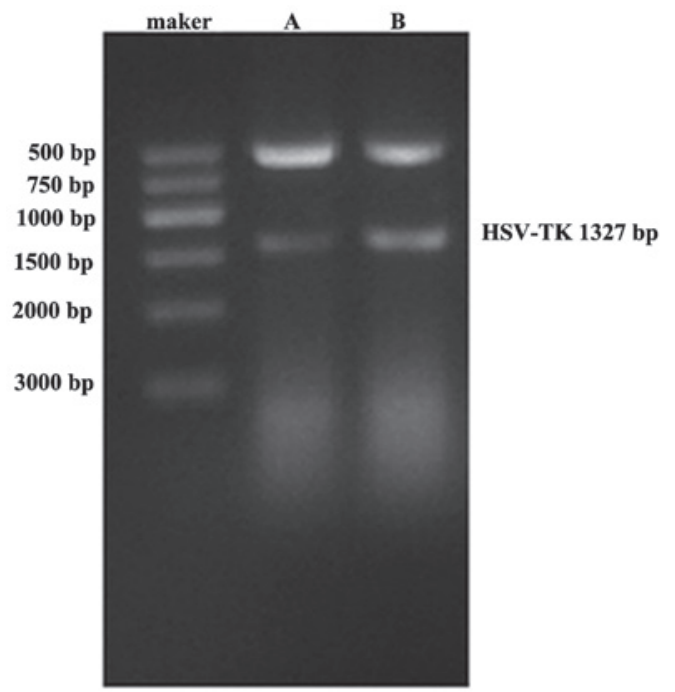

Figure 1. Detection of the expression of the TK gene by reverse transcription-quantitative polymerase chain reaction analysis in transfected HepG2 cells. (A) Positive control; (B) target gene. HSV-TK, herpes simplex virus-thymidine kinase.

with biotin-conjugated anti-Cx32 (1:100) at $4^{\circ} \mathrm{C}$ overnight. Goat anti-rabbit immunoglobulin G (IgG; cat. no. BS13271; Bioworld Technology, Inc.) was used as the negative control, at $37^{\circ} \mathrm{C}$ for $20 \mathrm{~min}$. The reaction was visualized using a SABC Standard kit (cat. no. SA1022; Wuhan Boster Biological Technology, Ltd., Wuhan, China), followed by counterstaining with hematoxylin. Serial sections were fixed in $10 \%$ zinc-buffered formalin and stained with hematoxylin and eosin. The sections were then incubated in PBS containing diaminobenzidine (Beyotime Institute of Biotechnology) for $5 \mathrm{~min}$, and examined under a microscope (CKX 41SF; Olympus, Tokyo, Japan).

Protein extraction and western blot analysis. The proteins were extracted using protein extraction reagent (Beyotime Institute of Biotechnology) $48 \mathrm{~h}$ following transfection, and stored at $-20^{\circ} \mathrm{C}$, as described previously (16). The protein extracts were obtained using a Membrane and Cytosol Protein Extraction kit (P0033; Beyotime Institute of Biotechnology), and protein concentration was determined using a Bradford assay kit (cat. no. P0006; Beyotime Institute of Biotechnology). Proteins were resolved by electrophoresis on $8 \%$ SDS-PAGE gels (Beyotime Institute of Biotechnology) and transferred onto polyvinylidene difluoride membranes (Thermo Fisher Scientific, Inc.). The membranes were immunoblotted with polyclonal rabbit anti-human anti-Cx32 (cat. no. BS3527; Bioworld Technology, Inc.; 1:500-1:1,000 dilution) overnight at $4^{\circ} \mathrm{C}$. The secondary antibody comprised horseradish peroxidase-conjugated monoclonal goat anti-rabbit (cat. no. BS13271; 1:10,000; Bioworld Technology, Inc.). The bands were analyzed using a GelGDoc2000 imaging system (Bio-Rad Laboratories, Inc., Hercules, CA, USA), and the protein levels were quantified by their relative OD.

Statistical analysis. The SPSS 17.0 statistical software package (SPSS, Inc., Chicago, IL, USA) was used to perform statistical analysis. The data are expressed as the mean \pm standard 

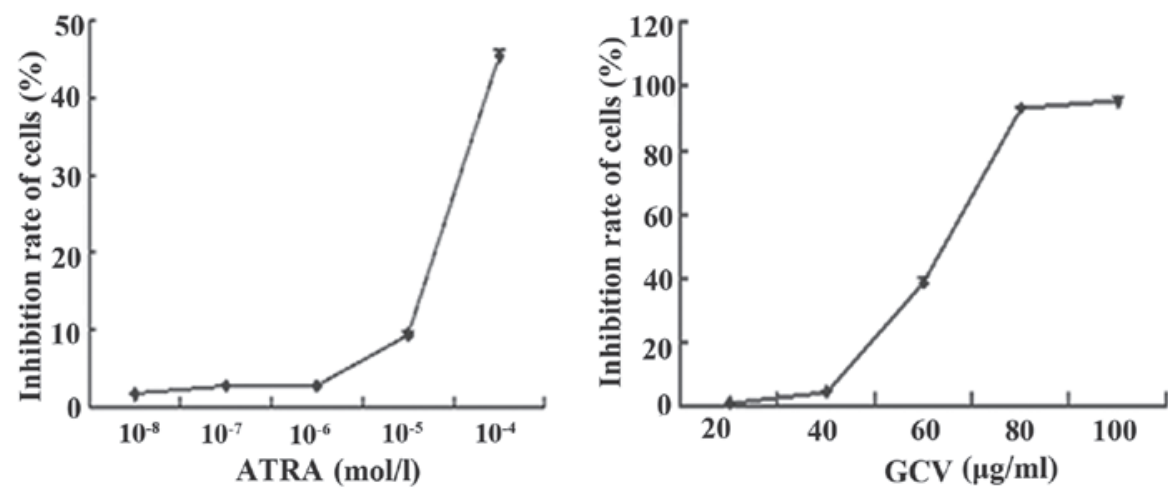

Figure 2. Assessment of the antitumor effects of ATRA and GCV by MTT. ATRA, trans-retinoic acid; GCV, ganciclovir.

deviation. Analysis of variance was used to assess the inhibition rate. A least significant difference $t$-test was used for pairwise comparisons. Kaplan-Meier's method was applied for survival analysis. $\mathrm{P}<0.05$ was considered to indicate a statistically significant difference.

\section{Results}

Expression of TK-specific $m R N A$ and cytotoxicity of ATRA and $G C V$. The mRNA expression of TK was observed in the HepG2 cells transfected using ultrasound microbubble-mediated with pIRES2-EGFP-HSVTK, compared with the positive control (Fig. 1). The rates of growth inhibition of the cells were $1.74 \pm 0.04,2.75 \pm 0.76,2.80 \pm 0.09,9.37 \pm 0.32$ and $45.38 \pm 0.72 \%$ at ATRA concentrations of $10^{-8}, 10^{-7}, 10^{-6}, 10^{-5}$ and $10^{-4} \mathrm{~mol} / \mathrm{l}$, respectively (Fig.2A). No apoptosis was observed in the cells exposed to ATRA alone, at concentrations as high as $10^{-6} \mathrm{~mol} / \mathrm{l}$, compared with the cells growing in the absence of ATRA $(\mathrm{P}>0.05)$, which showed no growth inhibitory effects. Toxic effects were observed when the concentration of ATRA was $>10^{-6} \mathrm{~mol} / \mathrm{l}(\mathrm{P}<0.05)$.

The rates of growth inhibition of the cells were 1.57 \pm 0.05 , $4.95 \pm 0.10,39.12 \pm 1.50,94.30 \pm 0.93$ and $95.38 \pm 1.12 \%$ at GCV concentrations of $20,40,60,80$ and $100 \mu \mathrm{g} / \mathrm{ml}$, respectively (Fig.2B). No significant difference in growth was observed in the cells exposed to GCV at concentrations up to $40 \mu \mathrm{g} /$ $\mathrm{ml}$, compared with the cells growing in the absence of GCV $(\mathrm{P}>0.05)$.

In vitro analysis of the bystander effect. To compare the potency of the bystander effect with or without ATRA, experiments were performed, in which $\mathrm{HSV}-\mathrm{TK}^{+}$and HSV-TK cells were mixed at varying ratios, followed by exposure to $40 \mu \mathrm{g} / \mathrm{ml}$ GCV, with or without $10^{-6} \mathrm{~mol} / 1$ ATRA. ATRA alone had no effect on the number of cells and this concentration of GCV had no effect on the growth of the cells. In the same proportion of $\mathrm{HSV}_{-} \mathrm{TK}^{+}$cells, a significant decrease in cell viability was observed in the ATRA-treated cells, compared with cells with ATRA treatment $(\mathrm{P}<0.05$; Fig. 3).

\section{In vivo experiments}

Treatment effect. As tumor size increased, the mice exhibited an emaciated body, appetite loss, dull furs, activity reduction and body weight loss. However, the growth of the mice in the treatment group was significantly improved, compared with that in the control group. Analysis of the tumor inhibition rates revealed that the tumor sizes in group D (HSV-TK+ATRA) were significantly lower $(\mathrm{P}<0.05)$, compared with those in the other groups. Compared with the HSV-TK group, the tumor sizes in the HSV-TK+ATRA group were smaller at all time points $(\mathrm{P}<0.05)$. The tumor inhibition rates of the PBS, HSV-TK, ATRA and HSV-TK+ATRA groups were 0, $37.97 \pm 4.35,6.92 \pm 7.41$ and $59.40 \pm 6.17 \%$, respectively (Fig. 3).

Histopathological changes and expression levels of Cx32 in tumor tissues. Compared with the other groups (Fig. 4A-C), higher levels of tumor cell necrosis were observed in the HSV-TK+ATRA group (Fig.4 D; P<0.05). Lower levels of cell necrosis and karyopyknosis were observed in the HSV-TK group, although these levels were higher, compared with the levels of cell necrosis in the PBS and ATRA groups. In analyzing the immunohistochemical staining, the brown-yellow or dark brown staining of the cytoplasm was considered positive (predominantly localized to the membrane of cells). Compared with the untreated group, the protein expression of $\mathrm{Cx} 32$ was significantly increased in the ATRA-treated tumor groups $(\mathrm{P}<0.01$; Fig. 4E and F). Similar results were obtained in the analysis of protein expression of Cx32 using Western blot analysis $(\mathrm{P}<0.05)$, in which the protein levels of $\mathrm{Cx} 32$ were significantly increased in the ATRA and HSV-TK+ATRA groups, compared with the other groups $(\mathrm{P}<0.01$; Fig. 5).

\section{Discussion}

$\mathrm{HCC}$ is one of the most common types of malignancy, which has a poor prognosis worldwide and frequently recurs following surgical or nonsurgical treatments, including transarterial chemoembolization, radiofrequency ablation, percutaneous ethanol injection therapy and chemotherapy (17). Newly established treatment methods, including gene therapy, can be combined with traditional treatments to destroy the tumor tissues. Prodrug/suicide gene therapy, which delivers a 'suicide' gene to target cells and renders them sensitive to a specific prodrug, is a promising strategy for the treatment of malignant tumors (18). The HSV-TK/GCV system is one of the most well-characterized systems and has been successfully used in vitro and in vivo for the treatment of malignancies (19-21). Numerous studies have shown that the treatment effect of the 

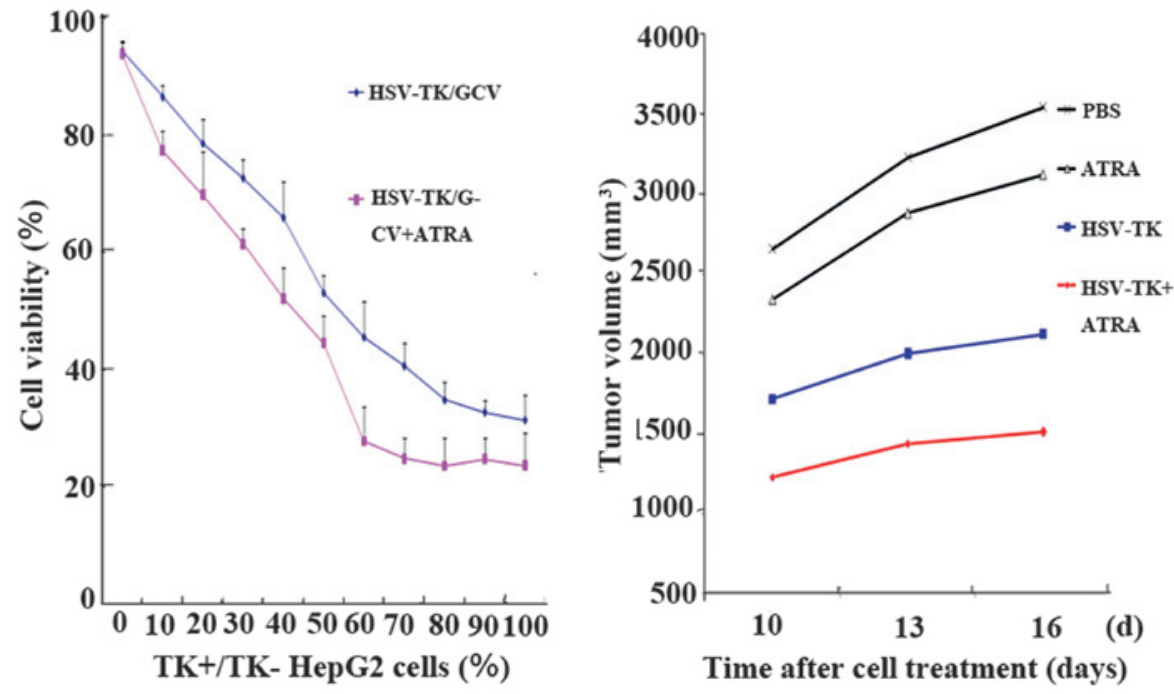

Figure 3. Analysis of the bystander effect in vitro and in vivo. Compared with the control group, the bystander effect was observed in the ATRA-treated cells, with reduced cell viability $(\mathrm{P}<0.05)$. Tumor inhibition rate in vivo. The bystander effect led to a reduction in tumor volumes in the HSV-TK/GCV+ATRA group, compared with the other groups $(\mathrm{P}<0.05)$, and in the HSV-TK group, compared with the PBS and ATRA groups $(\mathrm{P}<0.05)$. The results are expressed as the mean \pm standard deviation. PBS, phosphate-buffered saline; ATRA, trans-retinoic acid; HSV-TK, herpes simplex virus-thymidine kinase; GSV, ganciclovir.

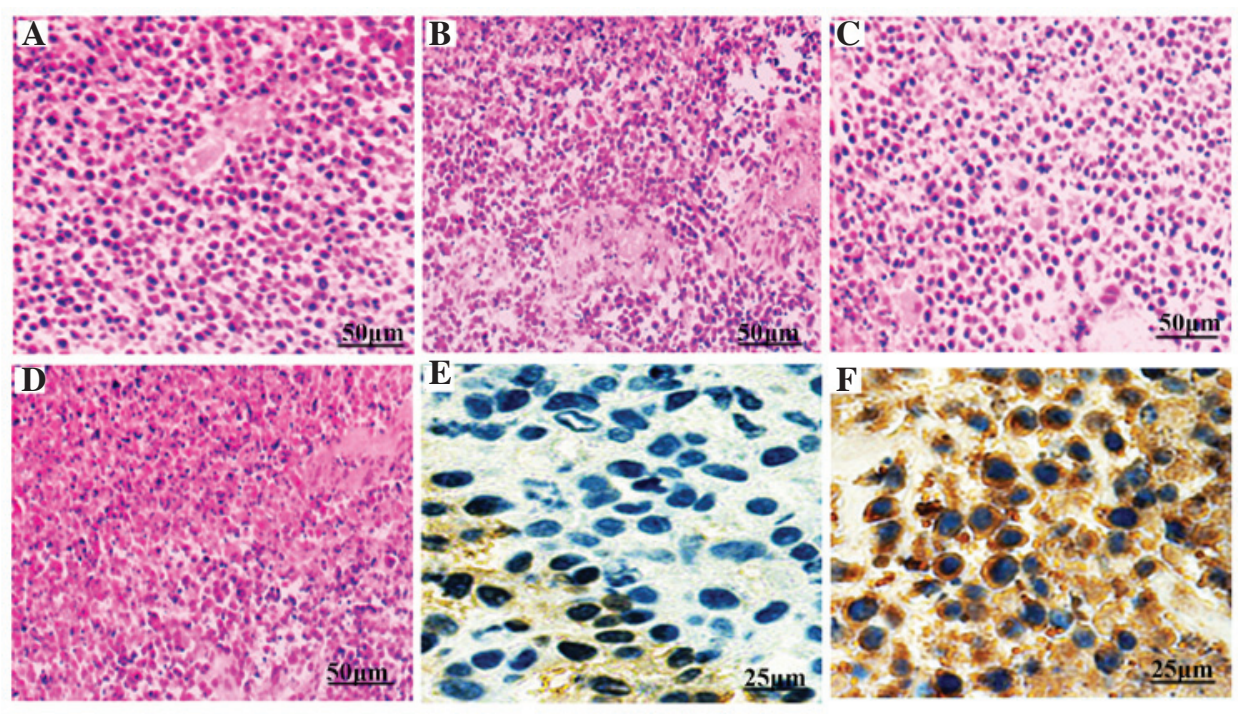

G

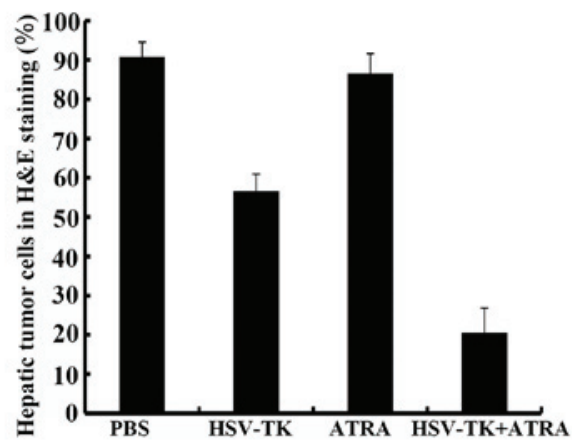

H

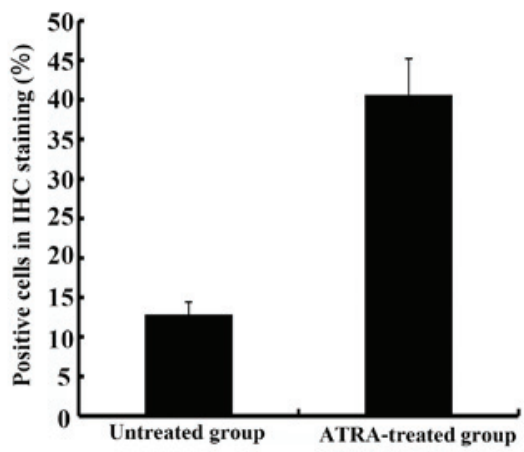

Figure 4. Hepatic tumor tissues stained with hematoxylin and eosin following treatment. Compared with the (A) PBS, (B) HSV-TK and (C) ATRA groups, higher levels of tumor cell necrosis were found in the (D) HSV-TK+ATRA group $(\mathrm{P}<0.05)$. Levels of cell necrosis and karyopyknosis were lower in the HSV-TK group, which showed higher levels of necrosis than the PBS and ATRA groups $(\mathrm{P}<0.05)$. Original magnification, $\mathrm{x} 200 ; \mathrm{scale}$ bar $=50 \mu \mathrm{m}$. Compared with the (E) untreated group, protein levels of Cx32 were higher in the (F) ATRA-treated group ( $\mathrm{P}<0.01)$. (G) Quantification of results. Compared with the other groups, there were fewer hepatic tumor cells in the HSV-TK+ATRA group $(\mathrm{P}<0.05)$. (H) Cx32 protein level was increased in the ATRA-treated tumor group $(\mathrm{P}<0.01)$, compared with the control group (untreated group). Original magnification, $\mathrm{x} 400$; scale bar $=25 \mu \mathrm{m}$. Cx 32 , connexin32BS, phosphate-buffered saline; ATRA, trans-retinoic acid; HSV-TK, herpes simplex virus-thymidine kinase. 

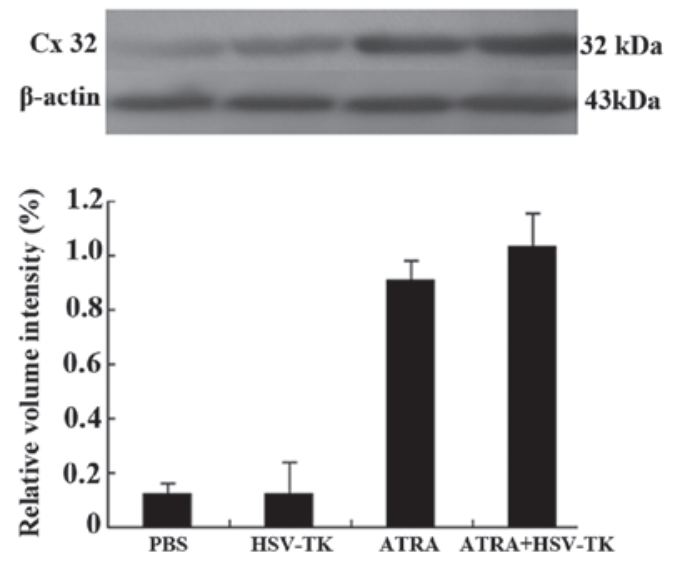

Figure 5. Protein expression of Cx32, measured using Western blot analysis. The protein expression levels of Cx32 in the ATRA and ATRA+HSV-TK groups were higher, compared with those in the other groups $(\mathrm{P}<0.01)$. The results are expressed as the mean \pm standard deviation. PBS, phosphate-buffered saline; ATRA, trans-retinoic acid; HSV-TK, herpes simplex virus-thymidine kinase; Cx32, connexin32.

HSV-TK/GCV suicide gene system is closely associated with the transfection efficiency of the TK gene and the bystander effect $(22,23)$.

The bystander effect of this system is explained by gap junctions, which transfer the GCV-triphosphate and other toxic metabolites among neighboring cells (24). GJIC has long been considered to be important in maintaining the bystander effect, wherein significant tumor regression can be achieved via bystander effects mediated by GJICs (25) composed of Cx protein.

GJIC is involved in the bystander effect of the HSV-TK/GCV system, possibly by allowing the passage of phosphorylated GCV metabolites between HSVTK + and HSVT cells. Gap junctions are formed and maintained by $\mathrm{Cx}$. The normal expression and correct localization of $\mathrm{Cx}$ in the cell membrane between neighboring cells is necessary to functionally channel GJIC. Therefore, GJIC is the primary mechanism for the bystander effect of the suicide gene. However, in the liver, Cx32 is the major and specific $\mathrm{Cx}$, and is often aberrantly located or reduced in tumor states, which leads to loss of GJIC function (26). GJIC has long been considered to be important in maintaining homeostasis and the control of cell growth (27). GJIC predominantly involves three connexins, Cx26, Cx32 and Cx43, depending on the cell type or cell position in the lobule (8). The expression of Cx32 is relatively specific in liver cells and is also one of the major gap junction proteins in hepatoma (28). In the present study, the expression of Cx32 was markedly increased in groups C and $\mathrm{D}$, and the apoptotic effect of the microbubble-mediated pIRES2-EGFP-HSV-TK suicide gene transfection via ultrasonic radiation was enhanced in vitro and in vivo, compared with groups A and B.

ARTA is important in a broad spectrum of biological processes, including inhibition of proliferation, regulation of apoptosis, induction of differentiation and control of development (29). ATRA is an ideal chemical inducer of GJIC and has a wide range of biological actions. Through binding to its receptors and a post-translational mechanism of action,
ATRA antagonizes the effects of two serine/threonine protein kinase families, protein kinase $\mathrm{C}$ and mitogen-activated protein kinase. This results in the phosphorylation of $\mathrm{Cx} 43$ and/or other Cx proteins, including Cx26 (30). In addition, it has been shown that ATRA enhances the tumoricidal effect of HSVTK/GCV suicide gene therapy against Daoy MB cells, by strengthening the bystander effect in vitro and in vivo (31). Similarly, the results of the present study revealed that ATRA significantly increased the expression of Cx32 in the HepG2 cells (Fig. 4 F), and significantly enhanced the bystander effect of the pIRES2-EGFP-HSV-TK/GCV system in the HepG2 cells (Figs. 2 and 3).

The results of the present study suggested that the HSV-TK/GCV suicide gene therapy system, mediated by Cx32 and combined with ATRA as an adjuvant, may have important implications for HCC treatment. The results of the in vitro experiments demonstrated a markedly enhanced apoptotic effect in the ATRA-treated cells, compared with ATRA-untreated cells, at the same proportion of $\mathrm{HSVTK}^{+}$ cells. In vivo, the tumor inhibition rate was $37.97 \%$ when treated with the HSV-TK suicide gene only, whereas the tumor inhibition rate was $59.4 \%$ in the HSV-TK+ATRA group. In addition the expression of $\mathrm{Cx} 32$ in tumor tissues or cells treated with ATRA was increased, with localization in a normal position. However, despite the experiments performed in the present study, a number of questions remain, including how ATRA increased the expression of $\mathrm{Cx}$, and whether other $\mathrm{Cx}$ proteins are involved in the antitumor effect. However, the potential side effects of ATRA may be reduced through use of the HSV-TK/GCV suicide gene system.

In the present study, an ultrasound mircobubble was used as the gene vector. The ultrasound microbubble-mediated delivery system has been used as a novel and effective gene delivery method (32-34). The ultrasound microbubbles-mediated HSV-TK suicide gene system not only improves gene targeting, but also increases the gene transfection efficiency due to the features of ultrasound and microbubbles. Ultrasound-targeted microbubble destruction technology is expected to become a novel gene delivery technique and may provide a novel strategy for targeted cancer therapy.

In conclusion, the results of the present study supported the suggested that the bystander effect ATRA, combined with delivery of the pIRES2-EGFP-HSV-TK/GCV system, can be an effective treatment for HCC. The mechanism appears to involve the induction of death of the proliferative HepG2 cells by enhancing the function of GJIC. The bystander effect may provide additional beneficial effects to that of promoter selectivity by eliminating neighboring, but uninfected, target cells (35). The clinical use of this type of gene therapeutic regimen require further investigation, and the formulation of the correct combination of therapeutic regimens and prediction of curative effects are also essential.

\section{Acknowledgements}

The present study was supported by the National Natural Scientific Foundation of China (grant no. 81272570), the National Natural Science Fund for Young Scholars (grant no. 81301975) and the Natural Science Foundation of Hubei Province of China (grant nos. 2014CFB310 and 2015CFB615). 


\section{References}

1. Liao YJ, Fang CC, Yen CH, Hsu SM, Wang CK, Huang SF, Liang YC, Lin YY, Chu YT and Arthur Chen YM: Niemann-Pick type $\mathrm{C} 2$ protein regulates liver cancer progression via modulating ERK1/2 pathway: Clinicopathological correlations and therapeutical implications. Int J Cancer 137: 1341-1351, 2015.

2. Qu L, Wang Y, Gong L, Zhu J, Gong R and Si J: Suicide gene therapy for hepatocellular carcinoma cells by survivin promoter-driven expression of the herpes simplex virus thymidine kinase gene. Oncol Rep 29: 1435-1440, 2013.

3. Yu BF, Wu J, Zhang Y, Sung HW, Xie J and Li RK: Ultrasound targeted HSVTK and Timp3 gene delivery for synergistically enhanced antitumor effects in hepatoma. Cancer Gene Ther 20: 290-297, 2013.

4. Xiao J, Zhang G, Qiu P, Liu X, Wu Y, Du B, Li J, Zhou J, Li J and Tan Y: Tanshinone IIA increases the bystander effect of herpes simplex virus thymidine kinase/ganciclovir gene therapy via enhanced gap junctional intercellular communication. PLoS One 8: e67662, 2013.

5. Wygoda MR, Wilson MR, Davis MA, Trosko JE, Rehemtulla A and Lawrence TS: Protection of herpes simplex virus thymidine kinase-transduced cells from ganciclovir-ediated cytotoxicity by bystander cells: The Good Samaritan effect. Cancer Res 57 1699-1703, 1997.

6. Lawrence TS, Rehemtulla A, Ng EY, Wilson M, Trosko JE and Stetson PL: Preferential cytotoxicity of cells transduced with cytosine deaminase compared to bystander cells after treatment with 5-flucytosine. Cancer Res 58: 2588-2593, 1998.

7. McLachlan E, Shao Q, Wang HL, Langlois S and Laird DW: Connexins act as tumor suppressors in three-dimensional mammary cell organoids by regulating differentiation and angiogenesis. Cancer Res 66: 9886-9894, 2006.

8. Maes M, Crespo Yanguas S, Willebrords $\mathrm{J}$ and Vinken $\mathrm{M}$ Models and methods for in vitro testing of hepatic gap junctional communication. Toxicol In Vitro 30: 569-577, 2015.

9. Garcia-Rodríguez L, Pérez-Torras S, Carrió M, Cascante A, García-Ribas I, Mazo A and Fillat C: Connexin-26 is a key factor mediating gemcitabine bystander effect. Mol Cancer Ther 10 : 505-517, 2011.

10. Banoub RW, Fernstrom M, Malkinson AM and Ruch RJ: Enhancement of gap junctional intercellular communication by dibutyryl cyclic AMP in lung epithelial cells. Anticancer Res 16 : 3715-3719, 1996.

11. Trottier C, Colombo M, Mann KK, Miller WH Jr and Ward BJ: Retinoids inhibit measles virus through a type I IFN-dependent bystander effect. FASEB J 23: 3203-3212, 2009.

12. Wolf G: Tissue-specific increases in endogenous all-trans retinoic acid: Possible contributing factor in ethanol toxicity. Nutr Rev 68: 689-692, 2010.

13. Zhou S, Li S, Liu Z, Tang Y, Wang Z, Gong J and Liu C: Ultrasound-targeted microbubble destruction mediated herpes simplex virus-thymidine kinase gene treats hepatoma in mice. JExp Clin Cancer Res 29: 170, 2010.

14. Wu L, Fu Z, Zhou S, Gong J, Liu CA, Qiao Z and Li S: HIF-1a and HIF-2 $\alpha$ : Siblings in promoting angiogenesis of residual hepatocellular carcinoma after high-intensity focused ultrasound ablation. PLoS One 9: e88913, 2014

15. Wang ZX, Wang ZG, Ran HT, Ren JL, Zhang Y, Li Q, Zhu YF and Ao M: The treatment of liver fibrosis induced by hepatocyte growth factor-directed, ultrasound-targeted microbubble destruction in rats. Clin Imaging 33: 454-461, 2009.

16. Aoi A, Watanabe Y, Mori S, Takahashi M, Vassaux G and Kodama T: Herpes simplex virus thymidine kinase-mediated suicide gene therapy using nano/microbubbles and ultrasound. Ultrasound Med Biol 34: 425-434, 2008.

17. Wang P, Sheng L, Wang G, Wang H, Huang X, Yan X, Yang X and Pei R: Association of transarterial chemoembolization with survival in patients with unresectable hepatocellular carcinoma. Mol Clin Oncol 2: 203-206, 2014.
18. Vachani A, Moon E, Wakeam E and Albelda SM: Gene therapy for mesothelioma and lung cancer. Am J Respir Cell Mol Biol 42: 385-393, 2010.

19. Määttä AM, Samaranayake H, Pikkarainen J, Wirth T and Ylä-Herttuala S: Adenovirus mediated herpes simplex virus-thymidine kinase/ganciclovir gene therapy for resectable malignant glioma. Curr Gene Ther 9: 356-367, 2009.

20. Kakinoki K, Nakamoto Y, Kagaya T, Tsuchiyama T, Sakai Y, Nakahama T, Mukaida N and Kaneko S: Prevention of intrahepatic metastasis of liver cancer by suicide gene therapy and chemokine ligand 2/monocyte chemoattractant protein-1 delivery in mice. J Gene Med 12: 1002-1013, 2010.

21. Yu DS, Zhao W, Huang HZ, Hu XW, Liu XQ and Tang HK: Synthetic radiation-inducible promoters mediated HSV-TK/GCV gene therapy in the treatment of oral squamous cell carcinoma. Oral Dis 16: 445-452, 2010.

22. Li Z, Tan Q, Ding Z and Liu D: Mechanism of DADS in the bystander effect of HSV-TK/GCV suicide gene therapy system in lens epithelial cells. Zhong Nan Da Xue Xue Bao Yi Xue Ban 36: 329-334, 2011 (In Chinese).

23. Yang J, Liu TJ, Jiang YX and Lu Y: ATRA enhances the bystander effect of suicide gene therapy driven by the specific promoter LEP 503 in human lens epithelial cells. Mol Vis 18: 2053-2066, 2012

24. Yang L, Chiang Y, Lenz HJ, Danenberg KD, Spears CP, Gordon EM, Anderson WF and Parekh D: Intercellular communication mediates the bystander effect during herpes simplex thymidine kinase/ganciclovir-based gene therapy of human gastrointestinal tumor cells. Hum Gene Ther 9: 719-728, 1998.

25. Sato T, Neschadim A, Lavie A, Yanagisawa T and Medin JA: The engineered thymidylate kinase (TMPK)/AZT enzyme-prodrug axis offers efficient bystander cell killing for suicide gene therapy of cancer. PLoS One 8: e78711, 2013.

26. Tang N, Wang Q, Wu D, Zhang S, Zhang Y and Tao L: Differential effects of paclitaxel and docetaxel on gap junctions affects their cytotoxicities in transfected HeLa cells. Mol Med Rep 8: 638-644, 2013.

27. Cronier L, Crespin S, Strale PO, Defamie N and Mesnil M: Gap junctions and cancer: New function for an old story. Antioxid Redox Signal 11: 323-338, 2009.

28. Thévenin AF, Kowal TJ, Fong JT, Kells RM, Fisher CG and Falk MM: Proteins and mechanisms regulating gap-junction assembly, internalization and degradation. Physiology (Bethesda) 28: 93-116, 2013.

29. Lin SC, Dollé P, Ryckebüsch L, Noseda M, Zaffran S, Schneider MD and Niederreither K: Endogenous retinoic acid regulates cardiac progenitor differentiation. Proc Natl Acad Sci USA 107: 9234-9239, 2010

30. Yang J, Liu TJ, Jiang YX and Lu Y: ATRA enhances the bystander effect of suicide gene therapy driven by the specific promoter LEP 503 in human lens epithelial cells. Mol Vis 18: 2053-2066, 2012

31. Li S, Gao Y, Pu K, Ma L, Song X and Liu Y: All-trans retinoic acid enhances bystander effect of suicide-gene therapy against medulloblastomas. Neurosci Lett 503: 115-119, 2011.

32. Panje CM, Wang DS and Willmann JK: Ultrasound and microbubble-mediated gene delivery in cancer: Progress and perspectives. Invest Radiol 48: 755-769, 2013

33. Sorace AG, Saini R, Rosenthal E, Warram JM, Zinn KR and Hoyt K: Optical fluorescent imaging to monitor temporal effects of microbubble-mediated ultrasound therapy. IEEE Trans Ultrason Ferroelectr Freq Control 60: 281-289, 2013.

34. Sorace AG, Warram JM, Umphrey $H$ and Hoyt K: Microbubble-mediated ultrasonic techniques for improved chemotherapeutic delivery in cancer. J Drug Target 20: 43-54, 2012.

35. Chen Y, Wang G, Kong D, Zhang Z, Yang K, Liu R, Zhao W and $\mathrm{Xu} Y$ : Double-targeted and double-enhanced suicide gene therapy mediated by generation 5 polyamidoamine dendrimers for prostate cancer. Mol Carcinog 52: 237-246, 2013. 